\title{
SYNTHESIS AND CHARACTERIZATION OF TIO, THIN FILM FOR \\ APPLICATION IN P3HT: PCBM ORGANIC SOLAR CELL
}

\author{
M. S. RAHIM, M. Z. SAHDAN, M.S. ALIAS, J. LIAS \& S. H. A. YUNUS \\ Microelectronics and Nanotechnology - Shamsuddin Research Centre (Mint-SRC) \\ Universities Tun Hussein on Malaysia (UTHM), Parit Raja, Batu Pahat, Johor, Malaysia
}

\begin{abstract}
Now with numerous novel and useful properties of TiO2 nano particles, it is widely manufactured and used in industries, which contribute to the development of nanotechnologies worldwide. The synthesis process to grow the TiO2 film was done by using the double zone chemical vapor deposition (CVD) technique and titanium but oxide (TiBu) as a precursor. Oxygen gas was used as a reaction gas to synthesized TiO2 film. The deposition process starts to set on the precursor temperature at $206{ }^{\circ} \mathrm{C}$ and glass substrate at $60{ }^{\circ} \mathrm{C}$. The TiO2 structure was grown to 4 different annealing of time after deposition process. The annealing temperature was kept at $500{ }^{\circ} \mathrm{C}$ in $20 \mathrm{~min}, 40 \mathrm{~min}, 50 \mathrm{~min}$ and $60 \mathrm{~min}$, respectively. The XRD pattern showed the highly oriented anatase phase at (101) peak orientation. The FESEM image showed a different surface of structure depended on parameter of annealing time. The 4-point probe measurement was used to measure resistivity for each parameter. The graph of transmittance measured by using UV-Vis Spectrophotometer. The best result depends on lower resistivity, the best parameter will deposit as a second buffer layer for P3HT: PCBM organic solar cell film. The electrical properties from I-V measurement show efficiency has improved because of TiO2 layer.

KEYWORDS: Tio2 Film, Anatase Phase, CVD, Annealing Time \& Organic Solar Cell
\end{abstract}

Received: May 18, 2017; Accepted: Jun 04, 2017; Published: Jun 13, 2017; Paper Id.: IJEEERJUN20176

\section{INTRODUCTION}

\section{Background}

In general, titanium dioxide (Titania, $\mathrm{TiO}_{2}$ ) is used typically for pigment applications [1] because of its brightness and very high refractive index. However, the interest or requests for other applications has increased rapidly during the past decade owing to its potential applications as a photovoltaic [2]; water splitting system [3]; and clean energy production [4], and water-purifying [5] material. Although a lot of the preceding applications using $\mathrm{TiO}_{2}$ in powder form, thin films of $\mathrm{TiO}_{2}$ has its own advantages and commercial uses as solar panels [6], antifogging glass [7], and self-cleaning glass [8].

The $\mathrm{TiO}_{2}$ is very attractive in technological application due to its structure morphology and crystalline phase [9]. $\mathrm{TiO}_{2}$ exists in three phases: anatase, rutile and brookite [10]. The active and almost studied crystallite phase $\mathrm{TiO}_{2}$ is anatase and rutile although brookite $\mathrm{TiO}_{2}$ was occasionally reported. It is usually that $\mathrm{TiO}_{2}$ in the anatase form is most photoactive and the most practical of the semiconductors technology [11].

In solar cell processing, $\mathrm{TiO}_{2}$ has established itself to a viable choice of antireflection coating due to its refractive index. Several techniques to synthesis $\mathrm{TiO}_{2}$ thin films, including sol-gel [12, 13], sputtering [14], anodic oxidation [15], electrophoretic deposition [16], pulsed laser deposition (PLD) [17], and electron-beam evaporation 
[18], and chemical vapor deposition (CVD) process [19]. In these cases, CVD represents an effective, versatile, and practical method to prepare $\mathrm{TiO}_{2}$ thin and thick films since it involves low costs, high purity and simple operation. Further, it does not require operation in vacuum, so the process can be done in ambient conditions.

Therefore, the main objective of this work is to synthesis and characterizes $\mathrm{TiO}_{2}$ film based on different of annealing time by using CVD technique. The best parameter will be deposit as second buffer layer to enhance the efficiency existing. In this following section, details of the experimental procedure, characterization of the parameter and result will be discussed.

\section{METHODS}

\section{Substrate Preparation}

$\mathrm{TiO}_{2}$ films were deposited on a glass substrate using CVD technique. The glass substrate was cut into $1.5 \mathrm{~cm} \times 1.5 \mathrm{~cm}$ using a diamond cutter. The glass was then cleaned using ethanol for 5 minutes and acetone for 5 minutes respectively in the ultra-sonic (Power-Sonic 405) bath at $50{ }^{\circ} \mathrm{C}$. This is because to eliminate the impurities residue at the glass substrate. After that, the glass was rinsed with deionized (DI) water and purge with nitrogen gas to ensure the glass is dry. The cleaning process must be conducted so that the glass is clean before deposition process, is also able to avoid any contaminating during and after the deposition process. Thus, impurities onto the glass can be reduced or eliminated.

\section{Deposition Process}

CVD technique is one of the simplest and economical techniques available for the synthesis of $\mathrm{TiO}_{2}$. The CVD technique was used to deposit $\mathrm{TiO}_{2}$ film using $1 \mathrm{ml}$ of liquid titanium but oxide (TiBu) and 0.1 1/min flow rate of oxygen $\left(\mathrm{O}_{2}\right)$ gas used as a reaction gas. From Figure 1(a) shows, alumina boat contained titanium but oxide entered in the quartz tube and in the middle of furnace 1. As well as the glass substrate, it will be placed into the quartz tube and in the middle of furnace 2. Figure 1(b) show furnace for annealing process in different of annealing time after deposition process.

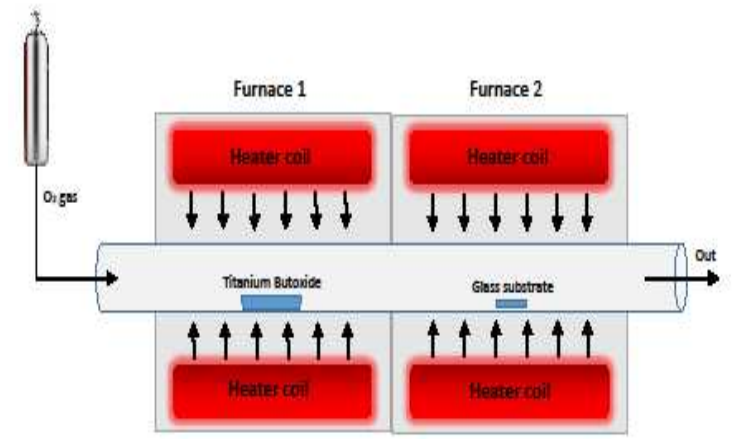

(a)

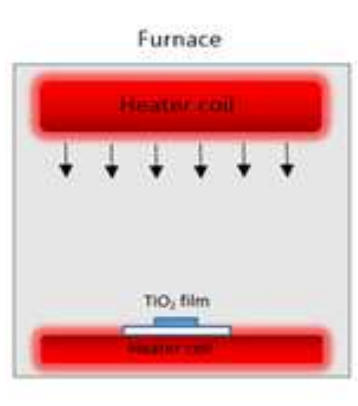

(b)

Figure1: Schematic Diagram for Deposition Process and Annealing Process

In this process, the temperature in the Furnace 1 should be set at $206{ }^{\circ} \mathrm{C}$ and furnace 2 needs to be set at $60{ }^{\circ} \mathrm{C}$. The temperature in furnace 1 is boiling point for titanium but oxide. Subsequently, after both furnaces reached the set value, oxygen gas should be open for allowed oxygen gas flow into quartz tube, because oxygen will react with titanium but oxide for deposit $\mathrm{TiO}_{2}$ film on the glass substrate in 30 minutes. After 30 minute reached, process deposit $\mathrm{TiO}_{2}$ film was done, the temperature will be cooling down to ambient temperature and oxygen gas should be closed in cooling down process. 
After deposition process, the $\mathrm{TiO}_{2}$ film should be annealed with four different time. The different time is 20 minutes, 40 minutes, 50 minutes and 60 minutes. The $\mathrm{TiO}_{2}$ film will annealed with ambient at $500{ }^{\circ} \mathrm{C}$ for 1 hour. Normally, the purposes of this process are to growth structure and remove all contamination onto film.

\section{RESULTS}

The crystalline phases of the coated beads were investigated using XRD analysis. The X-ray diffraction patterns of the $\mathrm{TiO}_{2}$ films with different of annealing time are presented in Figure 2. The presence of anatase phase was observed with all $\mathrm{TiO}_{2}$ film samples, indicating that they were not transformed from the anatase to rutile $\mathrm{TiO}_{2}$ structure. However, polycrystalline of anatase phase observed for film annealed in 60 minutes consist three peaks at $25.32^{\circ}, 37.86^{\circ}$ and $48.01^{\circ}$ (PDF No.98-015-4604) corresponding to (101), (004), and (200) planes of the anatase phase. The others samples shows single crystal structure of anatase at $25.32^{\circ}$. Generally, the anatase phase has higher photo catalytic activity efficiency compared to the rutile phase. From the patterns, it is confirmed that strong peak anatase phase exists in all parameters at 25.32 $2^{\circ}$ However, the sample with annealed in 60 minutes have a high crystalline compared to others sample. Therefore, annealing time is very important to form a good crystalline of structure.

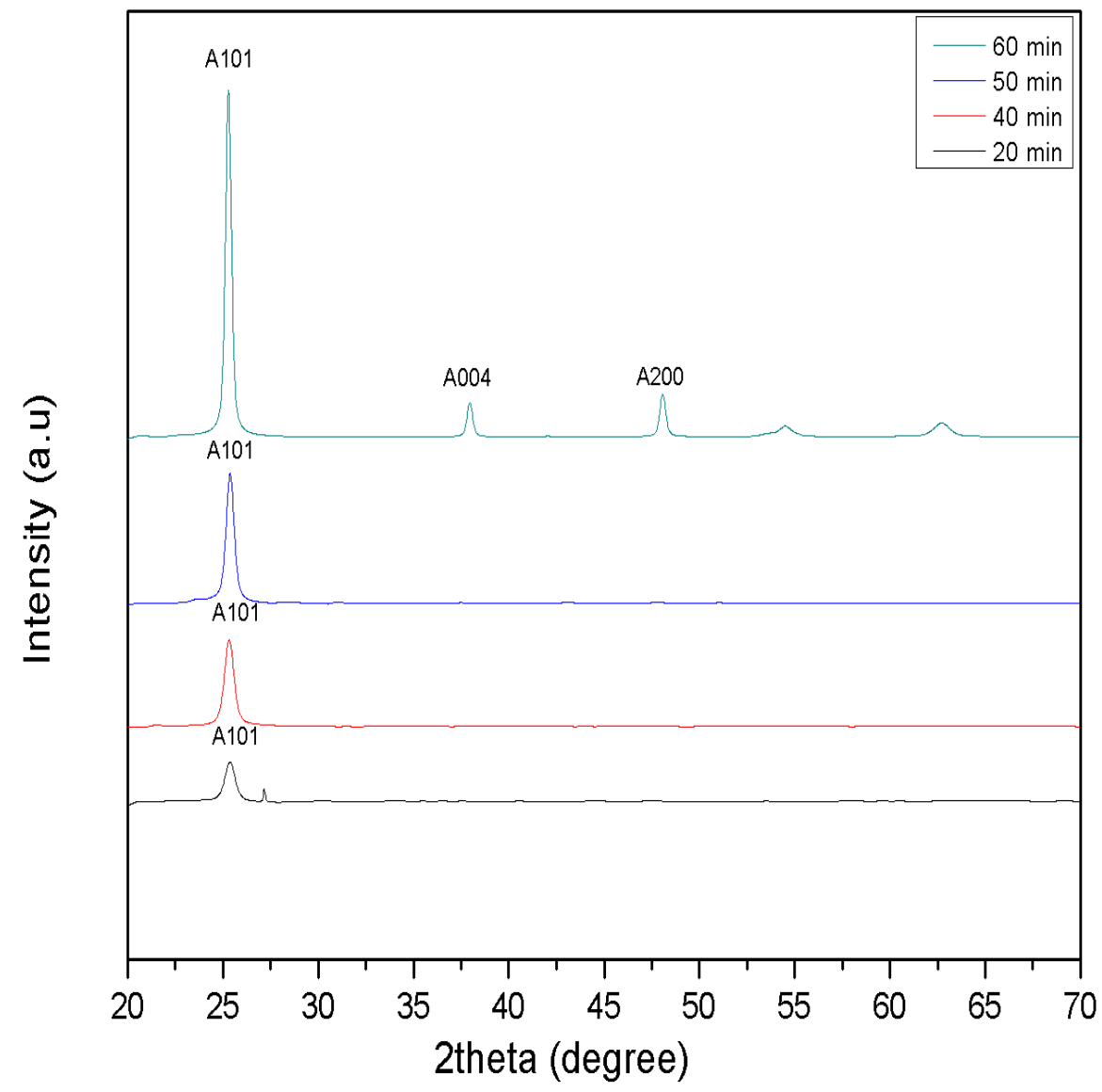

Figure 2: XRD Pattern for Different of Annealing Time 
Table 1: Average Crystallite Size and Full Width at Half Maximum for Phase at A (101) Plane.

\begin{tabular}{|c|c|c|}
\hline Different annealing of time & FWHM (deg.) & Average crystallite size (nm) \\
\hline 20 minutes & 0.481 & 0.33 \\
\hline 40 minutes & 0.576 & 0.27 \\
\hline 50 minutes & 0.629 & 0.25 \\
\hline 60 minutes & 0.354 & 0.45 \\
\hline
\end{tabular}

From table 1 shows, the average of crystallite size is inversely proportional to the FWHM, and thus, when the FWHM is smaller, the average crystallite size becomes biggest [20]. The highest average crystallite size value is sample annealed in 60 minutes. The average crystallite sizes of the films deposited at different annealing of time has been calculated using the Scherer's formula:

$$
L=\frac{0.9 \lambda}{\beta \cos \theta}
$$

Where, $\lambda=\mathrm{X}$-ray wavelength, $\lambda=1.5406 \AA, \theta=$ the Bragg's diffraction angle, and $\beta$ is the full width at half maximum (FWHM) of the peak corresponding to the " $\theta$ " value respectively.

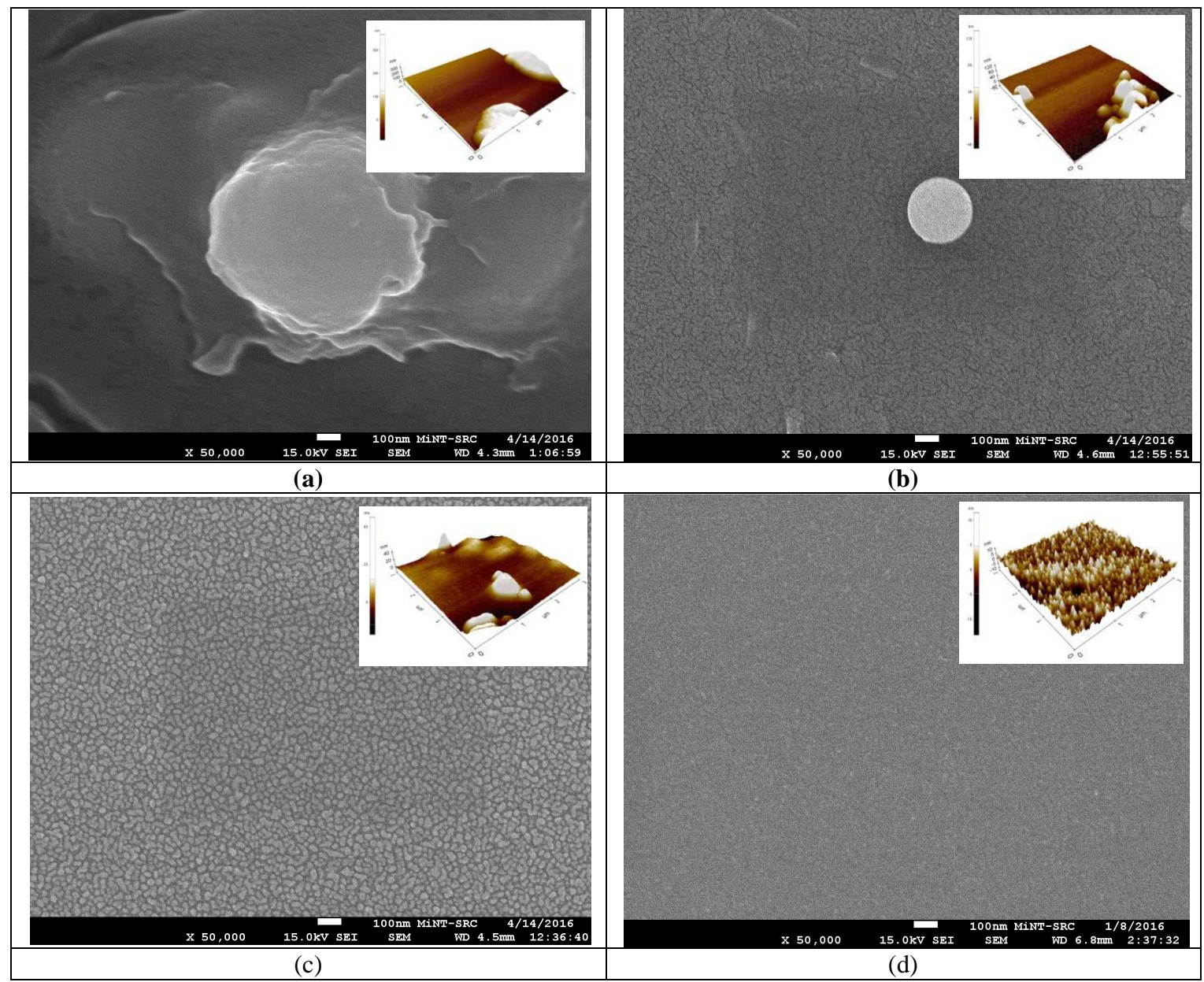

Figure 3: FESEM Image of Tio ${ }_{2}$ Films for Different of Annealing Time (A) 20 Minutes, (B) 40 Minutes, (C) 50 Minutes and (D) 60 Minutes and Inset are the AFM Topological Images at Respective Annealing Time 
The surface morphology of the structured $\mathrm{TiO}_{2}$ film has been studied using field emission scanning electron microscope (FESEM). Figure 3 shows the FESEM images of $\mathrm{TiO}_{2}$ film annealed at $500{ }^{\circ} \mathrm{C}$ in 20 minutes, 40 minutes, 50 minutes and 60 minutes, respectively. The FESEM image shows different surface images of $\mathrm{TiO}_{2}$ film depending on annealing time. Figure 3a shows that surface growth uneven and patches in some part of film. Correspondingly, atomic field microscope (AFM) analysis yielded a higher roughness value, which is RMS roughness is $63.412 \mathrm{~nm}$. Figure $3 \mathrm{~b}$, show not uniform film because still have some big particle around the $\mathrm{TiO}_{2}$ film and roughness for this film decrease to $23.645 \mathrm{~nm}$ compared 20 minutes. However, is different for image (c) and (d), it look uniform and homogenous films. As well as roughness, film for 50 minutes and 60 minutes more delicate with RMS roughness is $3.973 \mathrm{~nm}$ and $2.413 \mathrm{~nm}$. But, from Figure 3d more smooth and uniform structure compared Figure 3c which is not uniform and have cracking on surface. Therefore, the growth of nano phase crystalline $\mathrm{TiO}_{2}$ particles is accelerated at higher annealed time. In table 2 shows AFM analysis confirmed the presence of homogeneously distributed rounded particles, producing a film with a low roughness value with RMS roughness is $2.413 \mathrm{~nm}$. Annealing time is important to growth and shape the structure for a uniform film. An increase time for annealing process, average particle size rate drop from $816 \mathrm{~nm}$ to $20 \mathrm{~nm}$ as shown In table 2 .

Table 2: Data Roughness from AFM Measurement and Particle Size from FESEM Measurement

\begin{tabular}{|l|c|c|c|c|}
\hline \multicolumn{1}{|c|}{ Annealing Time } & 20 Minutes & 40 Minutes & 50 Minutes & 60 Minutes \\
\hline Roughness $(\mathrm{nm})$ & 63.412 & 23.645 & 3.973 & 2.413 \\
\hline Average particle size $(\mathrm{nm})$ & 816 & 259 & 45 & 20 \\
\hline
\end{tabular}

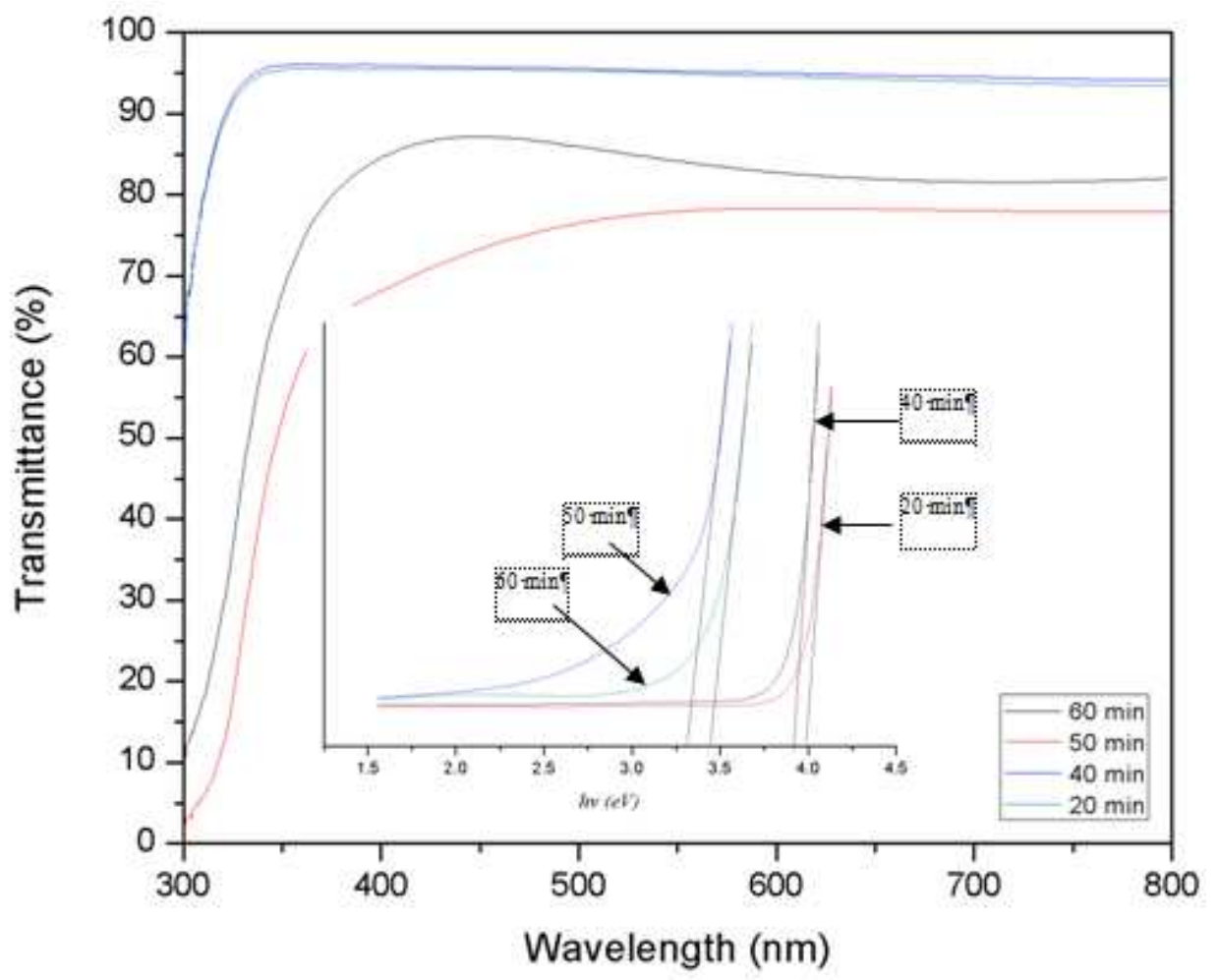

Figure 4: (A) Transmittance Spectra and (B) Band Gap for Tio 2 Film with Different Annealing of Time 
Band gap calculation using equation:

Band Gap Energy $(E)=h * C / \lambda$,

Where, $h=$ Planks constant $=6.626 \times 10^{-34}$ Joules sec, $C=$ Speed of light $=3.0 \times 10^{8}$ meter $/ \mathrm{sec}$ and $\lambda=$ Cut off wavelength $=410.57 \times 10^{-9}$ meters.

The transparency of the film exhibits a sharp decrease in the UV region. Figure 4 shows the transmittance spectra of the $\mathrm{TiO}_{2}$ film with different annealing of time. The transmittance for film annealing in 50 minutes is broader and slightly lower compared to 20, 40, and 60 minutes for all the wavelength range. However, transmittance for 20 minutes and 40 minutes very high transparency and almost the same pattern of graph along the wavelength range. This happened maybe due to $\mathrm{TiO}_{2}$ structure not growth well on film. Consequently, the glass does not fully cover with $\mathrm{TiO}_{2}$ structure. Even so, film annealing in 60 minutes exhibits slightly higher transmittance (i.e. 80\%) than 50 minutes and lower than 20 minutes and 40 minutes. It is one of the desirable features of the electrodes where the transmittances have been improved when annealing of time increase from 20 minutes to 60 minutes. From the transmittance graph, the optical band gap for 20 minutes is $3.9 \mathrm{eV}, 40$ minutes is $3.98 \mathrm{eV}, 50$ minutes is 3.30 and 60 minutes is $3.44 \mathrm{eV}$ based on band gap calculation (2).

Table 3: The Thickness and Resistivity for $\mathrm{Tio}_{2}$ Film with Different Annealing Condition

\begin{tabular}{|l|c|c|c|c|}
\hline \multicolumn{1}{|c|}{ Annealing Time } & 20 Minutes & 40 Minutes & 50 Minutes & 60 Minutes \\
\hline Thickness $(\mathrm{nm})$ & 178 & 279 & 342 & 431 \\
\hline Resistivity $(\Omega-\mathrm{cm})$ & $6.75 \times 10^{2}$ & $1.39 \times 10^{-1}$ & $1.61 \times 10^{-3}$ & $3.12 \times 10^{-4}$ \\
\hline
\end{tabular}

The resistivity of the $\mathrm{TiO}_{2}$ film was measured using 4-point probe measurement. Table 3 illustrates, the resistivity of the $\mathrm{TiO}_{2}$ film with different annealing of time depending on thickness. From table 3 obtained, thickness increase from $178 \mathrm{~nm}$ to $431 \mathrm{~nm}$ when annealing time increased. In contrast to the resistivity, when the time increases, the resistivity becomes lower. Accordingly, the lower resistivity is $3.12 \times 10^{-4} \mathrm{ohm}-\mathrm{cm}$ for annealing time in 60 minutes and the higher resistivity is $6.75 \times 10^{2} \mathrm{ohm}-\mathrm{cm}$ at annealing time in 20 minutes. From this result, depending on the lower resistivity, indicates that $\mathrm{TiO}_{2}$ film annealing in 60 minutes is the optimum film to use as a second buffer layer for P3HT: PCBM organic solar cell.

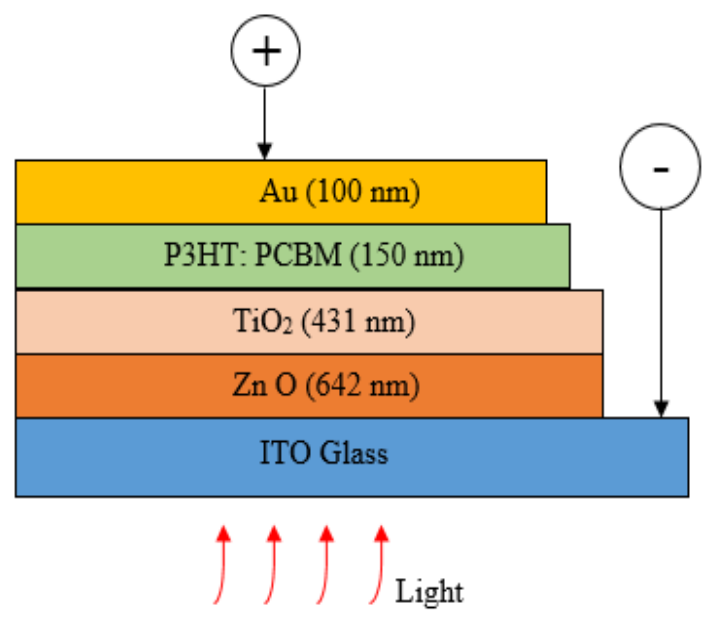

Figure 5: Schematic Device of $\mathrm{Tio}_{2}$ Film as a Buffer Layer after ZnO Layer 


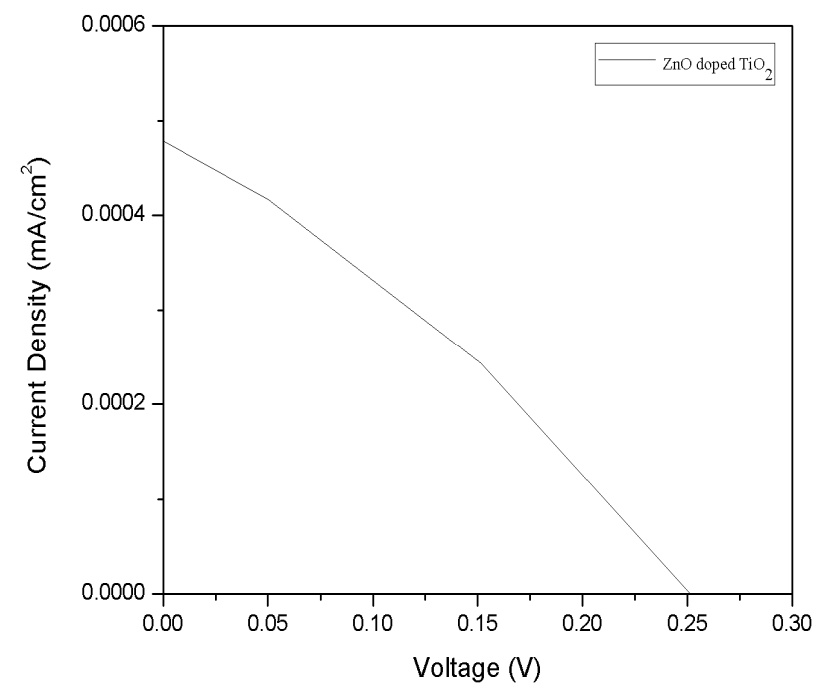

Figure 6: I-V Characteristics of Organic Solar Cell for $\mathrm{Tio}_{2}$ as a Buffer Layer after ZnO Layer

Table 4: The Organic Solar Cell Device Performance under Two Different Buffer Layer Condition

\begin{tabular}{|c|c|c|c|c|}
\hline Buffer layer & $\mathbf{V}_{\mathbf{~ o c}}(\mathbf{m V})$ & $\mathbf{J}_{\mathbf{s c}}\left(\mathbf{m A ~ ~ ^ { - 2 }}\right)$ & $\mathbf{F F}(\boldsymbol{\%})$ & PCE (\%) \\
\hline $\mathrm{ZnO}$ & 384 & 0.0447 & 19.01 & 0.0221 \\
\hline $\mathrm{ZnO}+\mathrm{TiO}_{2}$ & 251 & 5.315 & 30.4 & 0.4 \\
\hline
\end{tabular}

Figure 5 shows schematic device structure, with $\mathrm{TiO}_{2}$ film as a second layer as buffer layer after $\mathrm{ZnO}$ film. This test to know that $\mathrm{TiO}_{2}$ can improve the efficiency or not based on $\mathrm{ZnO}$ single layer organic solar cell. Table 4 has proved based on $I-V$ characteristic in Figure 6 . As shown in the figure, conversion, efficiency as high as $0.4 \%$ is obtained for cell with $\mathrm{ZnO}+\mathrm{TiO}_{2}$.

\section{CONCLUSIONS}

The synthesis and characterize of $\mathrm{TiO}_{2}$ films were prepared with different annealing of time which annealed at $500^{\circ} \mathrm{C}$ in 20 minutes, 40 minutes, 50 minutes and 60 minutes. The XRD data shows a strong peak (101) plane for anatase phase appears on every parameter. However, the high quality crystal was found for film annealed in 60 minutes. Because of that, the surface morphology for film annealed in 60 minutes has a uniform surface and homogeneity film with average particle size is $20 \mathrm{~nm}$. As well as roughness, show $2.413 \mathrm{~nm}$ the lowest compared to others parameter. The electrical resistivity obtained the lowest resistivity is $3.12 \times 10^{-4}$ related with band gap $3.44 \mathrm{eV}$ and high transparency over than $80 \%$ in the visible light range $300 \mathrm{~nm}$ to $800 \mathrm{~nm}$. Therefore, the optimum film is $\mathrm{TiO}_{2}$ film annealed in 60 minutes based on good crystalline, uniform surface structure, high transparency and low resistivity. Because of that, the optimum film has been used for a second layer mean that $\mathrm{TiO}_{2}$ film as a buffer layer after $\mathrm{ZnO}$ film. The $\mathrm{TiO}_{2}$ film proved that it could be a good layer to increase the efficiency of organic solar cell from $0.0221 \%$ to $0.4 \%$.

\section{ACKNOWLEDGMENTS AND LEGAL RESPONSIBILITY}

The authors are grateful to the Universities Tun Hussein on Malaysia with Grant contract VOT A043 which cooperation of Preston Shipyard Sdn. Bhd. 


\section{REFERENCES}

1. Byung. C. K, Soon. B. L, Jin. H. B. (2000). Surface and Coatings Technology, Growth of TiO $\mathrm{O}_{2}$ thin films on Si (100) substrates using single molecular precursors by metal organic chemical vapor deposition. 131, 88- 92. PII: S0257-8972(00)00765-9.

2. Noor. S. K, Siti. H. I, Mohd. K. A. (2015). Applied Mechanics and Materials, Effect of annealing time of TiO $\mathrm{O}_{2}$ thin film deposited by spray pyrolysis deposition method for dye-sensitized solar cell application, vols. 773- 774, pp 647- 651. Doi: 10.4028/www/scientific.net/AMM.773- 774.647.

3. Noor. D. M, Mohd. Z. S, Senain. I, Anis. S. B, Siti. A. A, Mokhter. F, Ahmad. K, Saim. S. (2016). ARPN Journal of Engineering and Applied Sciences, Effect of annealing temperature on structural, morphology and optical properties of TiO $\mathrm{O}_{2}$ thin film. Vol. 11, No.8. ISSN 1819-6608.

4. Shahzad. A. B, Ribeiro. C. (2016). Journal of photochemistry and photobiology C: Photochemistry reviews, Nitrogen-doped titanium dioxide: An overview of material design and dimensionality effect over modern applications. Vol 27, pp 1-9, Doi: http://dx.doi.org/10.1016/j.jphotochemrev.2016.05.001.

5. Mingyu. W. Xuewen. W. Puhong. Y. (2011). Journal of Hydrometallurgy, Recovery of vanadium from the precipitate obtained by purifying the wash water formed in refining crude TiCl4. pp 4 -43, doi:10.1016/j.hydromet.2011.08.005.

6. Hongche. N. Seong-Geun. O. Seung. S. I. (2015). Applied surface science, Preparation of anatase TiO2thin film by low temperature annealing as an electron transport layer in inverted polymer solar cells. pp 157-162, Doi: http://dx.doi.org/10.1016/j.apsusc.2015.02.010.

7. Zohra. N. K., Zobia. S., Saira. R., Shahzad. N., Farhat. S. (2016). Optik, Deposition of porous titanium oxide thin films as antifogging and anti-reflecting medium. pp 5124 - 5127. Doi: http://dx.doi.org/10.1016/j.ijleo.2016.03.009.

8. Angela.C. Mariateresa. L., Maurizio. M. (2016). Building and environment, Durability assessment of nano structured TiO2 coatings applied on limestone's to enhance building surface with self-cleaning ability. pp 1-10. Doi: http://dx.doi.org/10.1016/j.buildenv.2016.09.030.

9. Yang. L., Lulu. L., Min. G., Mei. Z. (2016). Journal of environmental science, Synthesis of TiO2 visible light catalysts with controllable crystalline phase and morphology from Ti-bearing electric arc furnace molten slag. pp 14-22, Doi: http://dx.doi.org/10.1016/j.jes.2015.11.032.

10. Fernandez-Domene. R.M., Sanchez-Tovar. R., Sanchez-Gonzalez. S. (2016). International journal of hydrogen energy, Photo electrochemical characterization of anatase-rutile mixed $\mathrm{TiO}_{2}$ nano sponges. pp. 18380-18388, Doi: http://dx.doi.org/10.1016/j.ijhydene.2016.08.012.

11. Zhao. Z., Xiang. Z., Juan. Y., Qingju. L. (2015). Article: rare metal material and engineering,

12. Effects of Nonmetal Doping on Electronic Structures and Optical Property of Anatase TiO2 from First-Principles Calculations. pp 44(7): 1568-1574.

13. Qiao. L.Y., Xie. F. Y., Xie. M. H., Gong. C. H., Wang. W. L., Gao. J. C. (2015). Transaction of nonferrous metals society of china, Characterization and photo electrochemical performance of Zn-doped TiO2 films by sol-gel method, pp 2109-2116. Doi: 10.1016/S1003-6326(16)64325-X.

14. Sangchay. W. (2016). Energy procedia, The self-cleaning and photo catalytic properties of TiO2 doped with SnO2 thin films preparation by sol-gel method. Pp 170-176. Doi: 10.1016/j.egypro.2016.05.023. 
15. Sawsen. N., Nadia. S., Samira. S., Faiz. M., Mogtaba. M. (2017). Applied surface science, Properties of TiO2thin films deposited by rf reactive magnetrons puttering on biased substrates. pp 172-179. Doi: http://dx.doi.org/10.1016/j.apsusc.2016.08.125.

16. Mazierski.. P., Nischk. M., Golkowska. M., Lisowski. W., Gazda. M., Winiarski. M.J., Tomasz. K., Adriana. Z. M. (2016). Applied catalysis B: Environmental, Photo catalytic activity of nitrogen doped TiO2nanotubes prepared by anodic oxidation: The effect of applied voltage, iodization time and amount of nitrogen do pant. pp 77-88. Doi: http://dx.doi.org/10.1016/j.apcatb.2016.05.006.

17. Krishna. R. C., Sudarsan. R., Yeon. T. Y. (2016). Journal of alloys and compounds, Synthesis and electrophoretic deposition of hollow-TiO2 nano particles for dye sensitized solar cell applications. pp 212-222. Doi: http://dx.doi.org/10.1016/j.jallcom.2016.02.164.

18. Minmin. H., Wenyuan. C., Hongjian.. G., Limin. Y., Bo. L., Junhong. Jia. (2016). Journal of power sources, Pulsed laser deposition of CuInS2 quantum dots on one-dimensional TiO2 nano rod arrays and their photo electrochemical characteristics. pp 121-127. Doi: http://dx.doi.org/10.1016/j.jpowsour.2016.04.011.

19. Monhanty. P., Kabiraj. D., Mandal. R.K., Kulriya. P.K., Sinha. A. S. K., Chandana. R. (2014). Journal of magnetism and magnetic materials, Evidence of room temperature ferromagnetism in argon/oxygen annealed TiO2 thin films deposited by electron beam evaporation technique. pp 240-245. Doi: http://dx.doi.org/10.1016/i.jmmm.2013.12.025.

20. Jun. D., Xiuyun. L., Kai. L. Xin. G., Wenqian. Q., Zhang. K. (2016). Journal of alloys and compounds, High hydrophilic Sidoped TiO2 nano wires by chemical vapor deposition. pp 893-897. Doi: http://dx.doi.org/10.1016/j.jallcom.2016.06.182.

21. Arunachalam. A., Dhanapandian. S., Manoharan. C. (2016). Physica E, Effect of Sn doping on the structural, optical and electrical properties of TiO2 films prepared by spray pyrolysis. pp 35-46. Doi: http:/dx.doi.org/10.10.2016/physe.2015.09.048. 
